\title{
High-Index Immersion Lithography
}

\author{
Keita Sakai \\ Canon Inc. \\ Japan
}

\section{Introduction}

The resolution capability of photolithography is given by Rayleigh's equation.

$$
\mathrm{R}=\mathrm{k}_{1} \cdot \lambda / \mathrm{NA},
$$

where $\mathrm{R}$ is the half-pitch resolution of the image, $\mathrm{k}_{1}$ is a constant that depends on the resist process and exposure method, $\lambda$ is the exposure wavelength, and NA is the numerical aperture of the projection optic. According to Rayleigh's equation, there are three ways to enhance the resolution. The first is to shorten the exposure wavelength such as extreme ultraviolet lithography (EUVL). The second is to improve the $\mathrm{k}_{1}$ value, for example, using the double-patterning technique. The third is to increase the numerical aperture (NA) as ArF immersion lithography. It has already realized the NA up to 1.35 and moreover can increase the NA using high-index materials. In this chapter, high-index immersion lithography with the NA over 1.45 is focused.

The NA is actually determined by the acceptance angle of the lens and the refractive index of the medium surrounding the lens and is given by eq. (2).

$$
\mathrm{NA}=\mathrm{n} \cdot \sin \theta \text {, }
$$

where $\mathrm{n}$ is the refractive index of the medium surrounding the lens and $\theta$ is the acceptance angle of the lens. Therefore, the NA can be enlarged by replacing the air $(n=1)$ with a fluid $(n>1)$ as a medium. In this immersion lithography, the film stack consists of a lens, a fluid layer, and a resist layer. The value of $n \cdot \sin \theta$ is invariant through the film stack because it obeys Snell's Law. Since $\sin \theta$ is smaller than 1 , the maximum NA $(=n \cdot \sin \theta)$ is limited by the layer with the minimum refractive index. For example, the refractive index of water is 1.44 at $193.4 \mathrm{~nm}$, thus the NA over 1.44 cannot be established as shown in Fig. 1 (a) because of the total reflection. To realize the NA over 1.44, the water must be replaced with a fluid which has a higher refractive index than water (Fig. 1 (b)). In Fig. 1 (b), fused silica has the smallest refractive index in the film stack and it limits the maximum NA. For further increasing the NA, a high-index lens material must be used as a lens material.

As described above, high-index lens materials and high-index immersion fluids are indispensable to realize high-index immersion lithography. One of the candidates of a highindex lens material is lutetium aluminium garnet (LuAG), which has a refractive index of 2.14. Second-generation (G2) and third-generation (G3) fluids are saturated hydrocarbon fluids whose refractive indices are approximately 1.64 and 1.80, respectively. 


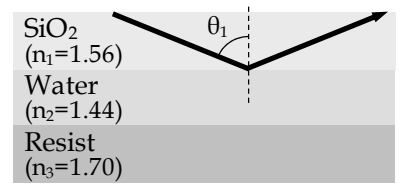

(a)

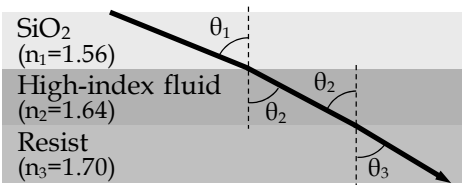

(b)

$$
\begin{aligned}
\mathrm{NA} & =1.45 \\
& =\mathrm{n}_{1} \cdot \sin \theta_{1} \\
& =\mathrm{n}_{2} \cdot \sin \theta_{2} \\
& =\mathrm{n}_{3} \cdot \sin \theta_{3}
\end{aligned}
$$

Fig. 1. Light propagation through the film stack at 1.45 NA. (a) The light does not reach the resist layer because of the total reflection at the lens-water boundary. (b) A high-index fluid enables the light to propagate into the resist.

High-index immersion lithography can be classified into three types by combining a lens material and an immersion fluid: fused silica and a G2 fluid (type 1), LuAG and a G2 fluid (type 2), and LuAG and a G3 fluid (type 3). With these types, the maximum NAs are estimated 1.45, 1.55, and 1.70, respectively.

Table 1 shows $\mathrm{k}_{1}$ values for typical half-pitch and NA. The $\mathrm{k}_{1}$ is calculated using Rayleigh's equation and needs to be at least 0.25 to resolve the patterns of the half-pitch for the theoretical limit. The resolution of $36 \mathrm{~nm}$ is achieved with 1.45 NA optic, which can be realized using only a G2 fluid. Those of $1.55 \mathrm{NA}$ and $1.65 \mathrm{NA}$ can achieve the resolutions of 34 and $32 \mathrm{~nm}$, respectively.

\begin{tabular}{cccccc}
\hline Half-pitch & $1.35 \mathrm{NA}$ & $1.45 \mathrm{NA}$ & $1.55 \mathrm{NA}$ & $1.65 \mathrm{NA}$ & $1.70 \mathrm{NA}$ \\
\hline $39 \mathrm{~nm}$ & 0.272 & 0.292 & 0.313 & 0.333 & 0.343 \\
\hline $36 \mathrm{~nm}$ & 0.251 & 0.270 & 0.289 & 0.307 & 0.316 \\
\hline $34 \mathrm{~nm}$ & 0.237 & 0.255 & 0.272 & 0.290 & 0.299 \\
\hline $32 \mathrm{~nm}$ & 0.223 & 0.240 & 0.257 & 0.273 & 0.281 \\
\hline
\end{tabular}

Table $1 . \mathrm{k}_{1}$ values for typical half-pitch and NA.

Although an exposure tool of 1.45 NA does not need new materials except for a G2 fluid, customers have little interest in the tool because of its modest gain in resolution. On the other hand, a tool of over 1.65 NA seems attractive for resolution enhancement. However, it would be difficult to realize G3 fluids immediately because no materials meet the requirements. In such a situation, it is a realistic way to develop a tool of 1.55 NA using LuAG and a G2 fluid.

In the next subchapter, projection optics with LuAG are explained. Development of LuAG is a hard work because the specifications of lithography-grade lens materials are extremely stringent. According to the history of LuAG development by Schott Lithotec (Parthier et al., 2008), great progress was achieved in the absorbance but it does not reach the target. The key issue for the optical design with LuAG is a correction of intrinsic birefringence (IBR). An effective method has been developed for IBR correction and it reduces the wave-front aberration to a practical level.

In the third subchapter, an immersion system using a G2 fluid is described. It was demonstrated that fluid absorbance can be kept low enough through an in-line purification unit and an oxygen removal unit. Although lens contamination is an important issue in a G2 fluid system, it was found that contamination can be suppressed by addition of a small amount of water into a G2 fluid. With this water-addition and in-line purification, the necessity for lens cleaning decreases from three times per day to once a week. Fluid 
confinement is also a challenge for a G2 fluid system because residual fluid is easy to remain on a wafer. Some issues arising with residual fluid, such as fluid darkening due to reentry of oxygen-rich residual fluid, were solved. By accepting residual fluid on a wafer, the scanning speed and the throughput can be raised.

Finally, the remaining challenges to realize high-index immersion lithography are discussed.

\section{Projection optics with LuAG}

Key parameters for high-index lens materials are refractive index, absorbance, and intrinsic birefringence (IBR). High-index lens materials must have a refractive index to permit NA scaling sufficient to justify the development cost. The absorbance must be sufficiently low to avoid the image degradation by thermal aberrations. The intrinsic birefringence must be minimal to allow a correction to avoid introducing unacceptable aberrations in the final aerial image.

The National Institute of Standards and Technology (NIST) has searched for high-index lens materials that meet the above requirements such as barium lithium fluoride $\left(\mathrm{BaLiF}_{3}\right)$ and LuAG (Burnett et al., 2006). $\mathrm{BaLiF}_{3}$ developed by Tokuyama is available in various sizes with low absorbance (Nawata et al., 2007). However, the refractive index of $\mathrm{BaLiF}_{3}$ is not high enough to achieve a sufficient NA for the enhancement of the resolution. Only LuAG remains as a candidate for a high-index lens material. LuAG has the intrinsic birefringence over $30 \mathrm{~nm} / \mathrm{cm}$ and still has a high absorbance caused by impurities. Thus, the status of LuAG should be paid attention to and an IBR correction method should be developed.

\subsection{Status of LuAG}

Lithography-grade LuAG has been aggressively developed by Schott Lithotec since 2005. The absorbance, which is the biggest issue for LuAG, was largely improved down to 0.035 $/ \mathrm{cm}$ by purifying the raw material and optimising the crystal growing process as shown in Fig. 2. Since it was found that the intrinsic absorbance of LuAG is $0.00118 / \mathrm{cm}$ (Letz et al., 2010), the absorbance will be less than $0.005 / \mathrm{cm}$ by further reduction of impurities.

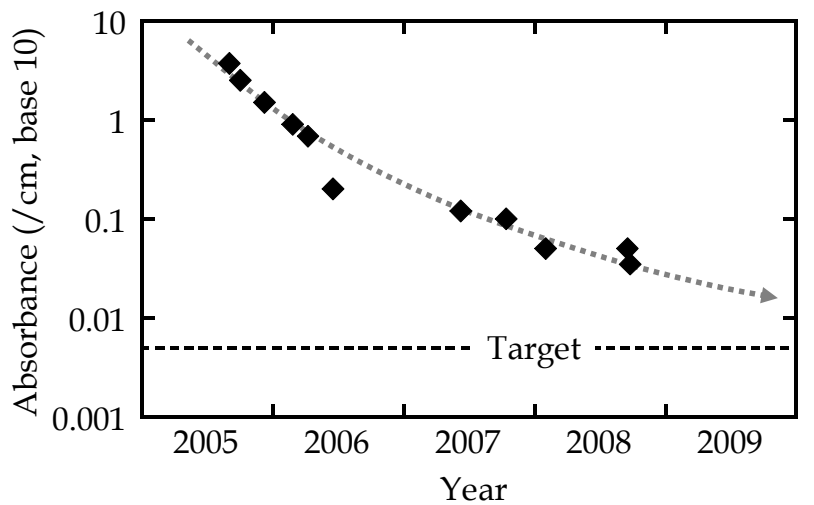

Fig. 2. History of LuAG development by Schott Lithotec. The absorbance of LuAG has been improved down to $0.035 / \mathrm{cm}$ but it has not reached the target $(0.005 / \mathrm{cm})$. 
Table 2 shows the target and the status of each requirement. The stress birefringence (SBR) and the homogeneity seem to have gotten closer to the targets. However, these were achieved with a small crystal of yttrium aluminium garnet (YAG). Therefore, it is necessary to confirm the SBR and the homogeneity of large-sized LuAG.

The remaining challenges, such as the absorbance, will be solved if the development is accelerated by strong supports from the industry.

\begin{tabular}{ccc}
\hline & Target & Status \\
\hline $\begin{array}{c}\text { Absorbance } \\
(/ \mathrm{cm}, \text { base 10) }\end{array}$ & $<0.005$ & 0.035 \\
\hline $\begin{array}{c}\text { Stress birefringence } \\
(\mathrm{RMS}, \text { nm/cm) }\end{array}$ & $<0.5$ & $\begin{array}{c}0.73 \\
(40 \mathrm{~mm} \phi, \mathrm{YAG})\end{array}$ \\
\hline $\begin{array}{c}\text { Index homogeneity } \\
(-\mathrm{Z} 36, \mathrm{ppm})\end{array}$ & $<0.05$ & $\begin{array}{c}0.03 \\
(45 \mathrm{~mm} \phi, \mathrm{YAG})\end{array}$ \\
\hline
\end{tabular}

Table 2. Target and status of LuAG.

\subsection{Intrinsic birefringence correction}

Since the absorbance of LuAG is higher than that of fused silica, it is difficult to use many LuAG lenses in a projection optic. From the viewpoint of optical design, applying LuAG to the final lens is most effective. In the final lens through which light converging at an image plane passes, the range of incident angles to the optical axis is wide. Assuming that the bottom surface of the final lens, which touches an immersion fluid, is flat, the maximum ray angles in LuAG are 46.4 and $52.6^{\circ}$ for the NAs of 1.55 and 1.70, respectively.

The IBR distribution depends on the direction of a crystal. The distribution of a (111)oriented crystal has three-fold rotational symmetry. When the (111)-oriented crystal is used, the angle at the maximum IBR is $35.3^{\circ}$ from the (111) axis. On the other hand, a (100)oriented crystal has four-fold rotational symmetry, and the angle at the maximum IBR is $45^{\circ}$ from the (100) axis. In short, the maximum ray angle exceeds both angles of the maximum IBR even in the case of NA 1.55.

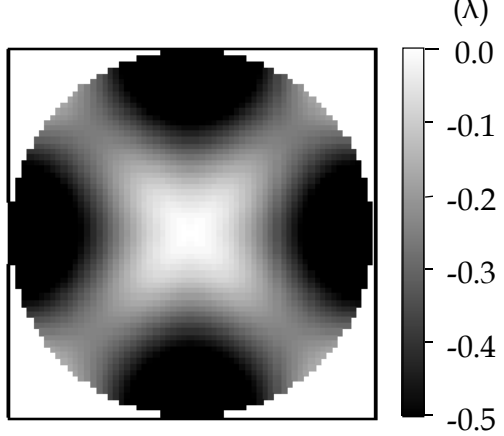

(a)

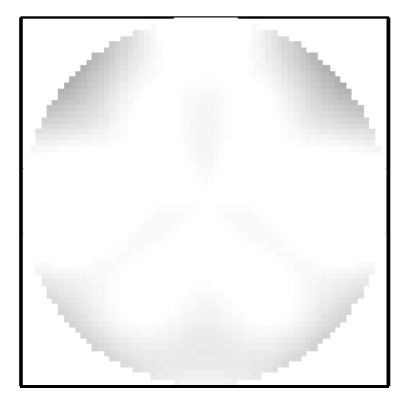

(b) $(\lambda)$

$-0.02$

$-0.04$

$-0.06$

$-0.08$

$-0.10$

Fig. 3. Difference between radial and tangential polarized wave front for a projection optic of $1.55 \mathrm{NA}$; (a) without IBR correction, (b) with an original correction method. 
Figure 3 shows wave front aberration maps for a projection optic of 1.55 NA. These show the difference between the radial and the tangential polarized wave fronts. The wave front difference without the correction has a large rms value of $217 \mathrm{~m} \lambda$ and a clear $4 \theta$ component. On the other hand, the original correction method reduces the rms difference to $4.2 \mathrm{~m} \lambda$. This value is within the practical level.

In the case of $1.70 \mathrm{NA}$, the wave front without the correction has a large rms difference of $680 \mathrm{~m} \lambda$ and the rms difference after the correction is $21.2 \mathrm{~m} \lambda$. Although this value is still large compared with the case of $1.55 \mathrm{NA}$, it is close to the practical level. Therefore, it can be concluded that the IBR correction is feasible even at $1.70 \mathrm{NA}$.

\section{Immersion system using a G2 fluid}

High-index immersion fluids are categorized as second-generation (G2) or third-generation (G3) fluids. G2 fluids have refractive indices of approximately 1.64 and enable an NA to increase up to 1.55 with LuAG as a final lens material. G3 fluids are targeted to have refractive indices over 1.80 for achieving an NA over 1.65 with LuAG.

DuPont, JSR, and Mitsui Chemicals have reported both G2 and G3 fluids (French et al, 2007, Furukawa et al., 2007, Kagayama et al., 2007). Their G2 fluids are saturated hydrocarbon and have sufficient performance as an immersion fluid. They also developed G3 fluids as some extension of organic G2 fluid materials. This type of G3 fluids has not yet met the requirements of refractive index or absorbance. The other types of G3 fluids, which include nanoparticles, are being developed, but they are still within the research phase (Zimmerman et al., 2008). In the above situation, an immersion system using a G2 fluid has been preferentially developed (Sakai et al., 2008).

To achieve the target cost of $\$ 1$ /layer for a G2 fluid, the recycling of a G2 fluid is required. G2 fluids are easily degraded by laser irradiation and the dissolution of oxygen from the atmosphere. Therefore, a fluid circulation system is desired to keep the fluid absorbance sufficiently low using purification and oxygen removal functions. In addition, lens contamination, bubble, and residual fluid on a wafer are also important issues. An immersion system composed of a fluid circulation system, an immersion nozzle and a cleaning unit should be established to accommodate a G2 fluid.

\subsection{Fluid degradation}

The absorbance of water does not change largely with dissolved oxygen, and immersion water is not used repeatedly as a G2 fluid. These are the reasons the degradation of water is not a concern as an immersion fluid.

On the other hand, the absorbance of a G2 fluid is easily increased by dissolved oxygen or laser irradiation. Moreover, the $\mathrm{dn} / \mathrm{dT}$ of a G2 fluid is $5 \sim 6$ times larger than that of water (French et al., 2006, Santillan et al., 2006, Furukawa et al., 2007). This means that a temperature change causes a larger change in the refractive index and results in larger thermal aberration (Sekine et al., 2007). To suppress a temperature rise with the absorption of exposure light, the fluid absorbance has to remain sufficiently low.

\subsubsection{Dissolved oxygen}

Although the absorbance of a G2 fluid is lower than that of water (French et al., 2005, Wang et al., 2006), the degradation of a G2 fluid with dissolved oxygen is larger than that of water. The 
first reason for this large degradation is the high oxygen solubility. It has been reported that the solubility of oxygen in G2 fluids are 55 70 ppm in air atmosphere (Furukawa et al., 2006). These values are 7 9 times higher than that in water. According to the research at Columbia University (Gejo et al., 2007), dissolved oxygen forms a charge-transfer complex with cycloalkane of a G2 fluid and the complex has strong absorption in the ultraviolet wavelength range. This is the second reason for the large degradation induced by dissolved oxygen.

The induced absorbance against dissolved oxygen in a G2 fluid has been experimentally obtained. Figure 4 shows the induced absorbance of HIL-203 (JSR) compared with water. It was confirmed that the oxygen-rich HIL-203 exhibits strong absorption. Therefore, a removal function of oxygen is necessary to keep the fluid absorbance low in a circulation system.

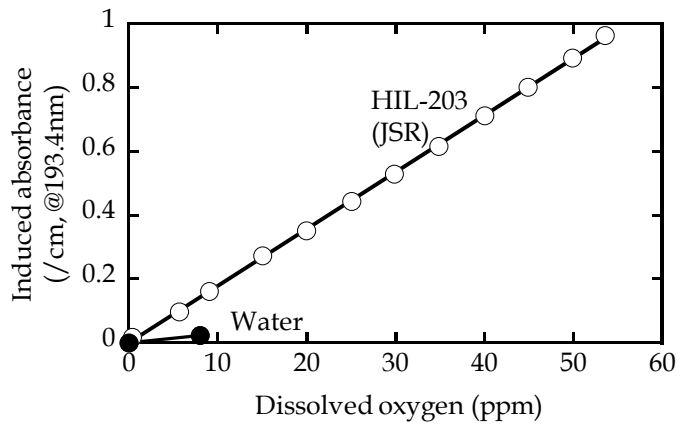

Fig. 4. Experimental results of induced absorbance with dissolved oxygen. Open circles show the induced absorbance of HIL-203 and filled circles show that of water.

An immersion nozzle supplies a G2 fluid under a final lens and sucks the fluid with the neighbouring gas. If the atmosphere around a wafer is air, the oxygen concentration in the recovered fluid increases with the sucked air. Under such a condition, two types of oxygen removal functions were evaluated using an experimental system as shown in Fig. 5. The fluid used in this experiment was HIL-203 (JSR) and the fluid flow rate was $400 \mathrm{~mL} / \mathrm{min}$.

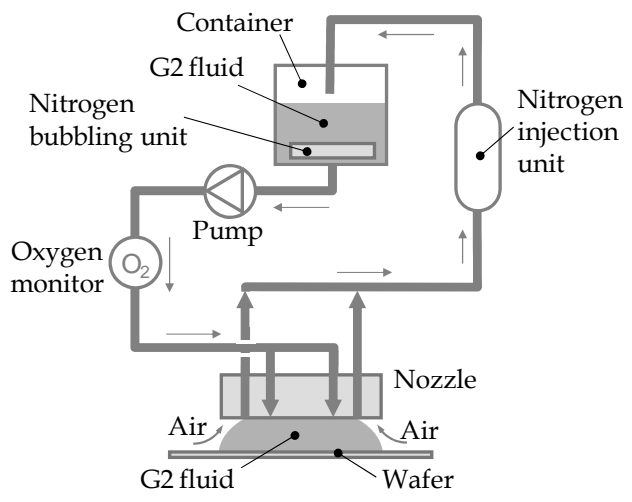

Fig. 5. Schematic view of an experimental system to investigate two types of oxygen removal functions. One is a nitrogen bubbling unit in the fluid container, and the other is a nitrogen injection unit attached to the fluid line. Oxygen concentration in the fluid is measured at the position just before the immersion nozzle. 
Figure 6 shows dissolved oxygen using two types of oxygen removal functions. In the case with the nitrogen bubbling unit alone, the oxygen concentration was $4.5 \mathrm{ppm}$. It corresponds to the absorption of $1.83 \% / \mathrm{mm}$, which can not be permitted. By using the nitrogen bubbling and the nitrogen injection units simultaneously, the oxygen concentration was reduced to $0.2 \mathrm{ppm}$. Further reduction was achieved increasing the nitrogen flow rate into the injection unit from 5 to $10 \mathrm{~L} / \mathrm{min}$. The oxygen concentration of $0.1 \mathrm{ppm}$ is the permissible level because it corresponds to only $0.04 \% / \mathrm{mm}$ degradation. The nitrogen injection unit removes the dissolved oxygen from the oxygen-rich fluid just after recovery and prevents the oxygen-rich fluid from going back to the container. That is why the injection unit is efficient for the reduction of dissolved oxygen.

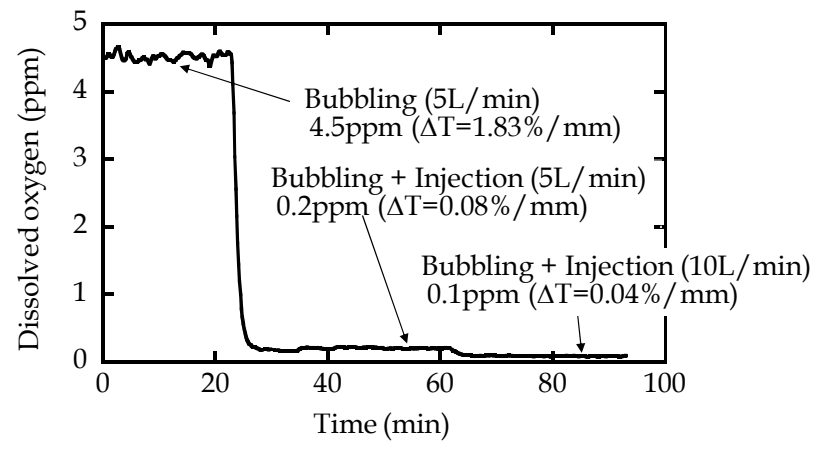

Fig. 6. Experimental results of dissolved oxygen using oxygen removal functions. At first, the dissolved oxygen was not sufficiently low with the nitrogen bubbling unit alone. Then, the large reduction of dissolved oxygen was achieved with the simultaneous use of the nitrogen bubbling and the nitrogen injection units.

\subsubsection{Laser irradiation}

The absorbance of a G2 fluid increases with the photodecomposed materials of a G2 fluid induced by ArF laser irradiation. To achieve the target cost of $\$ 1 /$ layer, it is necessary to remove the photodecomposed materials using an in-line purification unit.

Figure 7 shows the instruments used for a laser irradiation test. ArF excimer laser G41A3 (Gigaphoton), which can irradiate with the rep. rate of up to $3 \mathrm{kHz}$, is used for irradiation. The irradiation chamber has two beam lines and is purged with nitrogen gas to keep the oxygen concentration less than $1 \mathrm{ppm}$. The fluid circulation system with the oxygen removal functions can maintain dissolved oxygen at $0.1 \mathrm{ppm}$ and below. The fluid absorbance monitor contains four flow-through cells which can evaluate a number of fluids simultaneously.

The experimental conditions are shown in Table 3. Fluid suppliers have developed in-line purification units for their G2 fluid. Therefore, fluid degradation was evaluated with the combination of a fluid and a purification unit made by the same supplier, such as HIF-A and Unit-A.

The experimental results are shown as the induced absorbance against fluid dose. The fluid dose is defined as an incident dose modified by the volume dilution factor as shown in eq. (3). It has been suggested as the appropriate dose metrics (Liberman et al., 2007). 


$$
\mathrm{D}_{\text {fluid }}=\mathrm{I} \cdot \mathrm{N} \cdot \mathrm{V}_{\text {irr }} / \mathrm{V}_{\text {total }} \text {, }
$$

where $D_{\text {fluid }}$ is the fluid dose, $\mathrm{I}$ is the fluence per pulse, $\mathrm{N}$ is the total pulse count, and $\mathrm{V}_{\text {irr }}$ and $V_{\text {total }}$ are the irradiated volume and the total fluid reservoir volume, respectively.

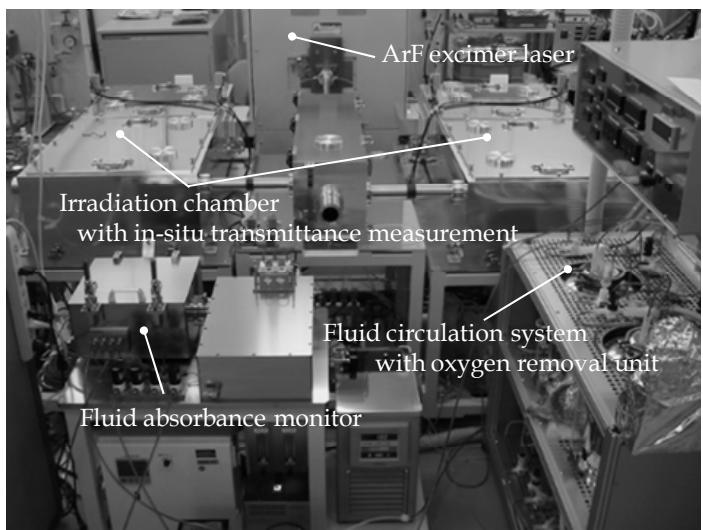

Fig. 7. Instruments for a laser irradiation test. The fluid circulation system consists of a fluid container, a pump, and oxygen removal units.

\begin{tabular}{cc}
\hline \multirow{2}{*}{ Immersion fluid / Purification unit } & $\begin{array}{c}\text { HIF-A / Unit-A } \\
\text { HIF-B / Unit-B } \\
\text { HIF-C / Unit-C }\end{array}$ \\
\hline Fluence & $0.5 \mathrm{~mJ} /\left(\mathrm{cm}^{2} \cdot\right.$ pulse $)$ \\
\hline Rep. rate & $2000 \mathrm{~Hz}$ \\
\hline Irradiation area & $8.0 \mathrm{~mm} \phi$ \\
\hline Fluid gap & $1.0 \mathrm{~mm}$ \\
\hline Fluid flow rate & $100 \sim 350 \mathrm{~mL} / \mathrm{min}$ \\
\hline
\end{tabular}

Table 3. Experimental conditions for evaluation of in-line purification units.

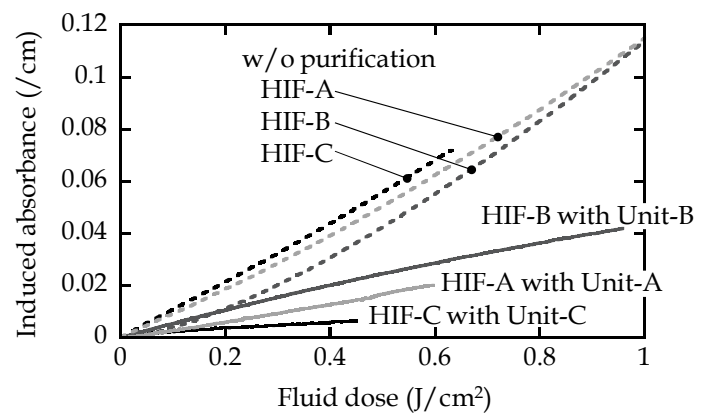

Fig. 8. Induced absorbance of a G2 fluid against the fluid dose. The dashed line shows the induced absorbance without a purification unit. The solid line shows the result with a purification unit. The fluid dose is calculated using eq. (3) and the conditions as shown in Table 3. 
Figure 8 shows the induced absorbance of each G2 fluid with and without an in-line purification unit. For example, the degradation rate of HIF-C with Unit-C is one-seventhfold smaller than that without Unit-C. Using a purification unit, fluid lifetime will be up to 1 week before the fluid absorbance will reach an unacceptable level. Therefore, it can be concluded that recycling of a G2 fluid is feasible using an in-line purification unit.

\subsection{Lens contamination}

It has been reported that the exposed surface of a final lens is polluted by photodecomposed materials of a G2 fluid (French et al., 2007). This lens contamination diminishes the uniformity of exposure dose on a wafer and would be a source of particles. Thus, the suppression of lens contamination is a serious issue for an immersion system using a G2 fluid.

The suppression of lens contamination was examined by three procedures. The first is to select an appropriate fluid, which has a lower deposition rate. The second is to use an in-line purification, which can remove photodecomposed materials. The third is water-addition into a G2 fluid, which is an original suppression method.

Figure 9 shows a schematic diagram of the experimental setup. The cell absorbance, which consists of the absorbance of windows and a fluid of $1 \mathrm{~mm}$ path length in the cell, was measured using two power meters. In addition, the fluid absorbance was measured by a fluid absorbance monitor. Then, the absorbance of windows was calculated by subtracting the fluid absorbance from the cell absorbance as shown in eq. (4).

$$
\mathrm{A}_{\text {window }}=\mathrm{A}_{\text {cell }}-\mathrm{A}_{\text {fluid }} \text {, }
$$

where $A_{\text {window }}$ is the absorbance of windows, $A_{\text {cell }}$ is the cell absorbance, and $A_{\text {fluid }}$ is the fluid absorbance through $1 \mathrm{~mm}$ path length.

The laser fluence was $1.0 \mathrm{~mJ} /\left(\mathrm{cm}^{2}\right.$.pulse), which is almost the same as in an actual exposure tool. The dose estimation on an actual tool is approximately $60 \mathrm{~kJ} /\left(\mathrm{cm}^{2}\right.$.day). Although the effective cleaning method was proposed (Liberman et al., 2007), the necessity for lens cleaning should be less than once a week for minimizing tool downtime.

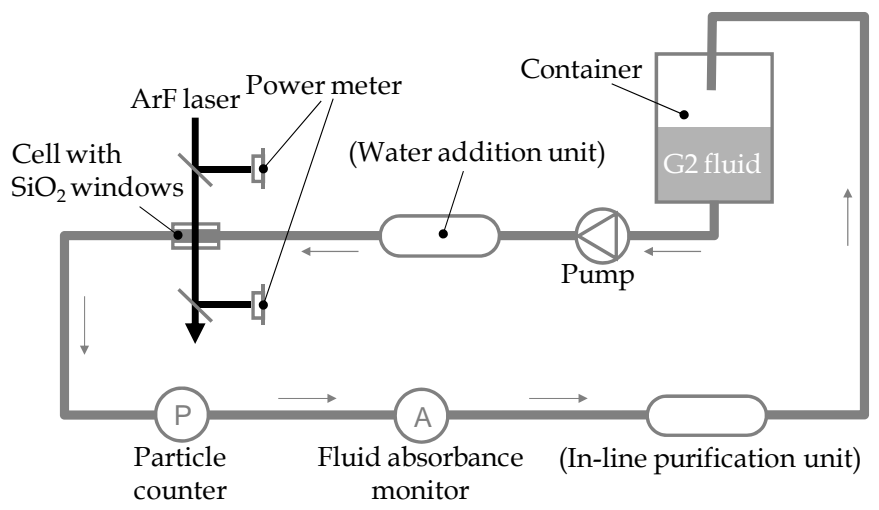

Fig. 9. Schematic diagram of the experimental setup. G2 fluid flows through the $1 \mathrm{~mm}$ gap space between the $\mathrm{SiO}_{2}$ windows of the irradiation cell. The particle counter can detect particles larger than $60 \mathrm{~nm}$ in diameter. 


\subsubsection{Appropriate fluid}

Induced absorbance of windows, which correspond to a final lens of a projection optic, was evaluated by using various G2 fluids. Figure 10 shows induced absorbance of windows against exposure dose. HIF-C exhibits a higher deposition rate than HIF-A and D. Therefore, HIF-A or D should be selected from the point of view of lens contamination. However, lens contamination occurs in a few hours on an actual exposure tool, even if using HIF-A or D. It is necessary to introduce some methods for suppressing contamination.

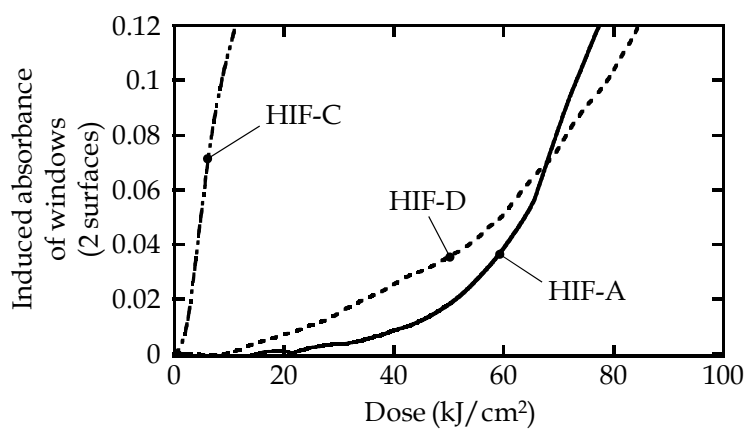

Fig. 10. Induced absorbance of windows using various $\mathrm{G} 2$ fluids. The deposition rates of HIF-A (solid line) and HIF-D (dashed line) are lower than that of HIF-C (dashed-dotted line).

\subsubsection{In-line purification}

It is expected that an in-line purification unit can suppress lens contamination because it can reduce photodecomposed materials. The experiments with several G2 fluids and in-line purification units were carried out using the experimental setup as shown in Fig. 9.

Figure 11 shows experimental results of window absorbance with and without a purification unit. It was confirmed that each purification unit can improve lens contamination. But the performance of purification units are not enough and a final lens needs to be cleaned more than once a day under the practical use conditions. Therefore, the additional method is desired to extend the cleaning interval.

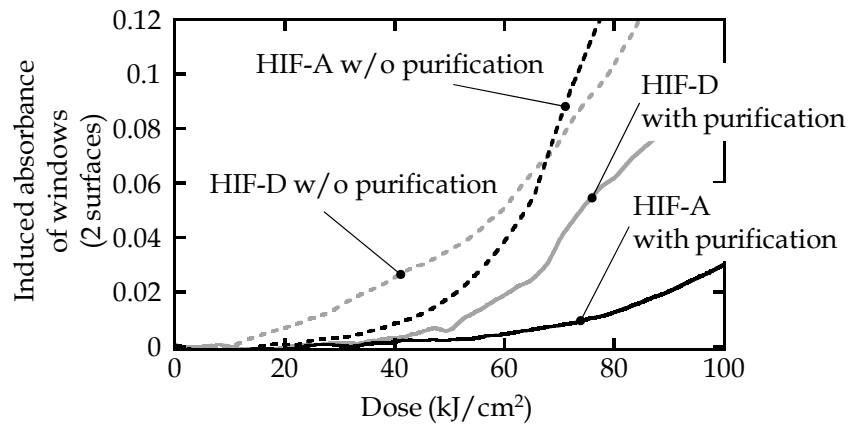

Fig. 11. Induced absorbance of windows with and without a purification unit. The deposition rate with a purification unit (solid line) is lower than that without a purification unit (dashed line). 


\subsubsection{Water-addition}

It was found that lens contamination can be suppressed by addition of a small amount of water into a G2 fluid (Sakai et al., 2008). Since water in a G2 fluid is removed by an oxygen removal unit or an in-line purification unit, a water-addition unit is necessary for a fluid circulation system to keep water in a G2 fluid. Figure 12 shows a schematic diagram of a water-addition unit. Using the water-addition unit, a sufficient amount of water can be solved into a G2 fluid.

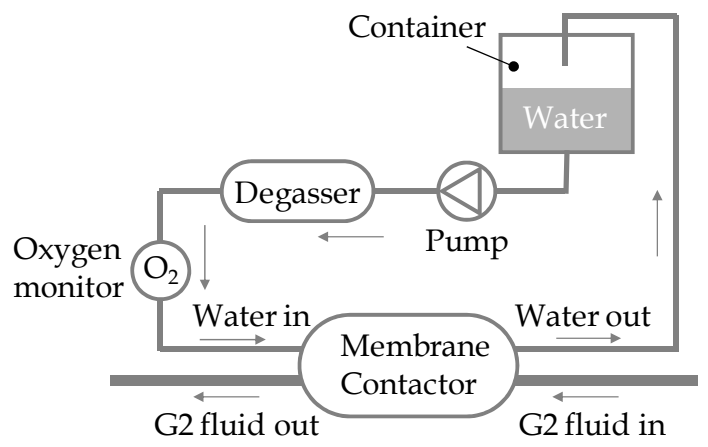

Fig. 12. Schematic diagram of a water-addition unit. The unit consists of a membrane contactor and a circulation unit of degassed water. Degassed water contacts a G2 fluid through the porous membrane with a large area.

Figure 13, 14, and 15 shows the experimental results using HIL-203 (JSR) as a G2 fluid. In the case without water-addition, the absorbance of windows increased gradually (Fig. 13) and many streak contaminations were observed on the window (Fig. 14 (a)). On the other hand, the window was not contaminated in the case with water-addition (Fig. 13, Fig. 14 (b)). A strong impact was also obtained in terms of particle. As shown in Fig. 15, particles increased with lens contamination in the case without water-addition. Some portions of lens contamination would be removed by laser irradiation and flow into the fluid as particles. Using the water-addition unit, there were no particles in the fluid made from lens contamination. It was also confirmed that the water-addition unit does not generate any particles.

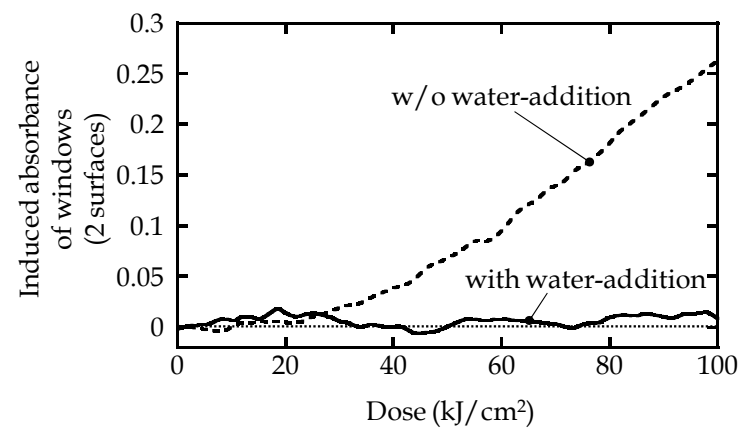

Fig. 13. Induced absorbance of windows against exposure dose. The absorbance of windows increased with the exposure dose in the case without water-addition (dashed line). In contrast, the water-addition unit suppressed contamination (solid line). 
As described above, water-addition is the superior method for suppressing lens contamination. In addition, it seems to be a method without any disadvantages. For example, the refractive index of a G2 fluid does not change substantially with wateraddition because the solubility of water into a G2 fluid is very low (several tens of ppm).

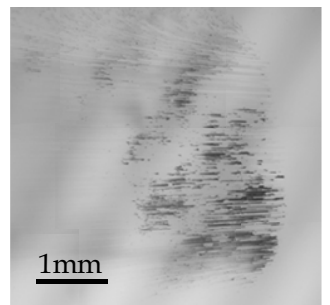

(a)

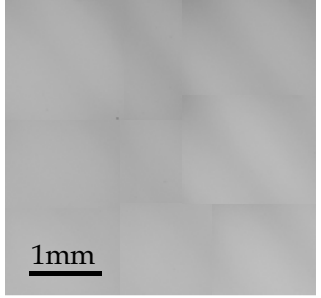

(b)

Fig. 14. Micrographs of window surfaces; (a) without water-addition after $100 \mathrm{~kJ} / \mathrm{cm}^{2}$ exposure, (b) with water-addition after $100 \mathrm{~kJ} / \mathrm{cm}^{2}$ exposure.

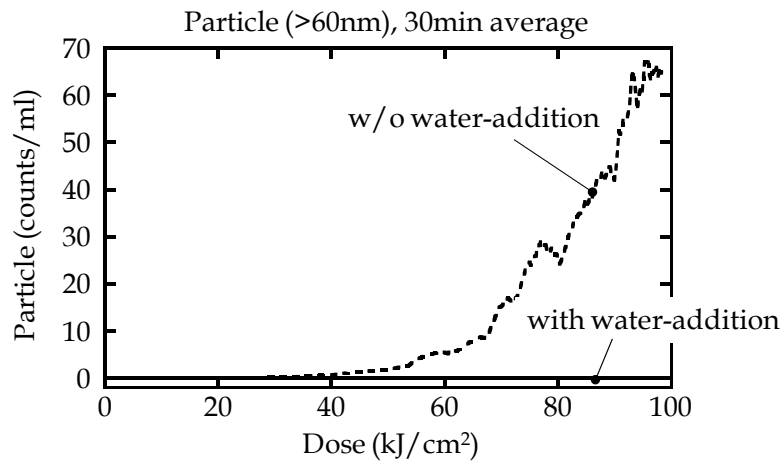

Fig. 15. Particles in a fluid against exposure dose. The number of particles increased with the exposure dose without water-addition (dashed line). In contrast, the water-addition unit suppressed particles induced by lens contamination (solid line).

\subsubsection{Long-term test}

A long-term test for lens contamination was done with an in-line purification unit and a water-addition unit simultaneously. IF132 (DuPont) and ARP (DuPont) were used as a G2 fluid and an in-line purification unit, respectively.

As shown in Fig. 16, the absorbance of windows started to increase at $20 \mathrm{~kJ} / \mathrm{cm}^{2}$ without any suppression units. The dose estimation on an actual exposure tool is approximately 60 $\mathrm{kJ} /\left(\mathrm{cm}^{2}\right.$.day). Therefore, lens cleaning must be done three times per day in this case. Even if with ARP, the absorbance started to rise at $60 \mathrm{~kJ} / \mathrm{cm}^{2}$ and a lens needs to be cleaned once a day. The cleaning interval is not allowed in the case with ARP alone. On the other hand, lens contamination was suppressed until $420 \mathrm{~kJ} / \mathrm{cm}^{2}$ using ARP and a water-addition unit simultaneously. The necessity for lens cleaning is once a week and it is practical. Figure 17 shows micrographs of window surfaces after the experiments. The micrographs also exhibit 
that the simultaneous use of ARP and a water-addition unit has a sufficient performance. It is concluded that lens contamination is not a critical issue anymore.

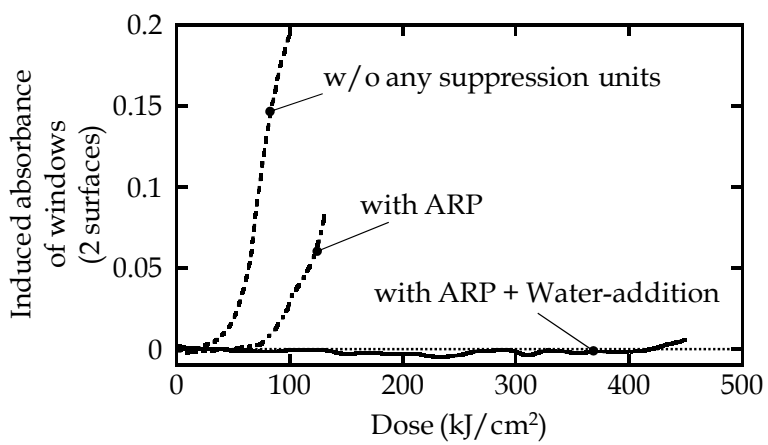

Fig. 16. Induced absorbance of windows against exposure dose. Simultaneous use of ARP and a water-addition unit suppressed lens contamination until $420 \mathrm{~kJ} / \mathrm{cm}^{2}$.

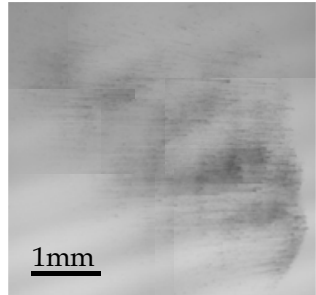

(a)

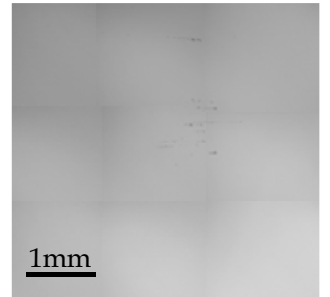

(b)

Fig. 17. Micrographs of window surfaces; (a) with ARP after $130 \mathrm{~kJ} / \mathrm{cm}^{2}$ exposure, (b) with $\mathrm{ARP}$ and a water-addition unit after $450 \mathrm{~kJ} / \mathrm{cm}^{2}$ exposure.

\subsection{Bubble}

A bubble is one of the origins of immersion defect. A bubble is entrapped on an air-liquid boundary and is translated with a wafer motion. If the bubble lifetime is sufficiently short, the bubble will be eliminated before reaching an exposure area. Therefore, the reduction of bubble lifetime is important.

The gas in a bubble diffuses from the surface of the bubble into the fluid. This diffusion causes the bubble to shrink with time and to eventually vanish. The bubble lifetime is approximated using eq. (5) (Honda et al., 2004).

$$
\tau=\frac{\rho d^{2}}{8 D\left(C_{S}-C_{\infty}\right)}
$$

where $\tau$ is the bubble lifetime, $\rho$ is the density of the gas inside the bubble, $d$ is the diameter of the bubble, $\mathrm{D}$ is the diffusion coefficient, $\mathrm{C}_{S}$ is the saturated concentration, and $\mathrm{C}_{\infty}$ is the concentration of the dissolved gas at a position far from the bubble. Figure 18 shows a schematic diagram of the experimental setup for the bubble lifetime measurement. By 
increasing the pressure of the fluid from 1 to $2 \mathrm{~atm}$, the bubble vanishes at a certain lifetime. It corresponds to the lifetime in the half-degassed fluid. Figure 19 shows the bubble lifetimes in water and two types of G2 fluids. The experimental results in water correlated with the theory fairly well. The bubble lifetime in the G2 fluid was shorter than that in water. Hence, the concept of the bubble elimination method for a water immersion system, i.e., using degassed fluid, is also feasible in an immersion system using a G2 fluid.

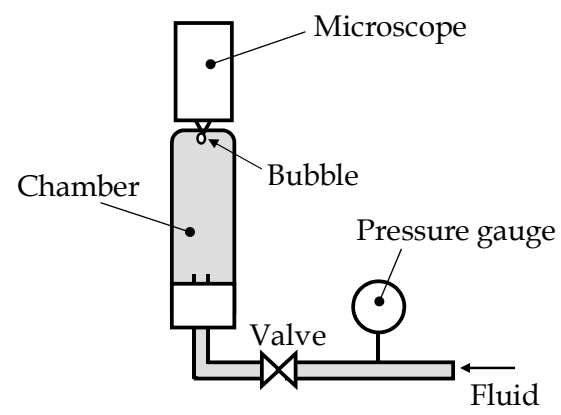

Fig. 18. Schematic diagram of the experiment setup for the bubble lifetime measurement. The size of a bubble is observed using the microscope.

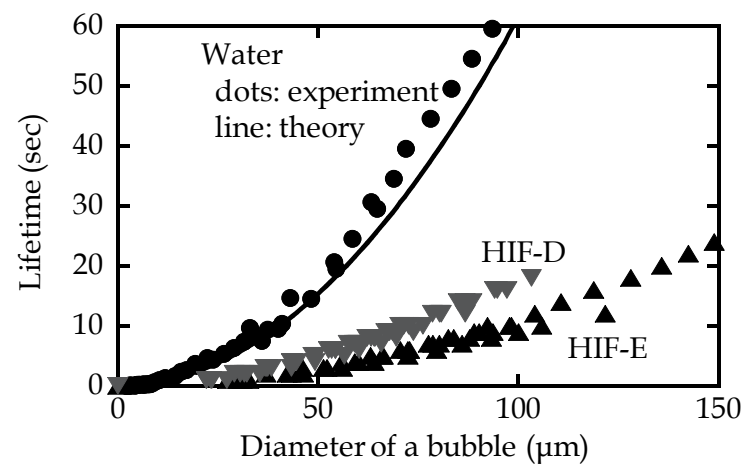

Fig. 19. Bubble lifetimes in various fluids. The lifetimes in G2 fluids (triangles) are shorter than that in water (circles).

\subsection{Residual fluid on a wafer}

The surface tension and viscosity of water are $72 \mathrm{mN} / \mathrm{m}$ and $1 \mathrm{mPa} \cdot \mathrm{s}$, respectively. This extremely high surface tension and low viscosity enable the immersion nozzle to keep water under a final lens (Kubo et al, 2007). On the other hand, it has been reported that a G2 fluid is easy to remain on a wafer (Sewell et al, 2007). After the verification that residual fluid is hard to avoid, some issues arising with residual fluid are discussed. The experimental results for the issues, such as the interaction between a G2 fluid and a resist, metal contamination in a G2 fluid, and fluid darkening due to oxygen-rich residual fluid, are explained. 


\subsubsection{Scanning test}

The surface tension and viscosity of G2 fluids are approximately $30 \mathrm{mN} / \mathrm{m}$ and $2 \sim 4 \mathrm{mPa} \cdot \mathrm{s}$, respectively. The film pulling velocity $\left(\mathrm{v}_{\mathrm{fp}}\right)$, which is the minimum scanning velocity to leave fluid behind the nozzle, is proportional to the surface tension $(\gamma)$ and the inverse of the viscosity $(\mu)$ as shown in eq. (6) (Shedd et al., 2006). If a wafer has the same static receding contact angle (SRCA, $\theta_{\mathrm{s}, \mathrm{r}}$ ) for water and a G2 fluid, the film pulling velocity for a G2 fluid is approximately one-sixth-fold lower than that for water. Although the higher SRCA can increase the film pulling velocity, the target SRCA over $120^{\circ}$ is too high to develop an appropriate topcoat material (Sanders et al., 2008). Therefore, it is difficult to achieve a sufficient scanning speed without residual fluid in an immersion system using a G2 fluid.

$$
v_{f p}=C \frac{\gamma}{\mu} \theta_{s, r}^{3}
$$

where $\mathrm{C}$ is the empirical constant.

Figure 20 shows the results of the fundamental scanning test using a prototype topcoat for G2 fluids. HIL-203 (JSR) was used as a G2 fluid for the experiment. Even with the scanning speed of $30 \mathrm{~mm} / \mathrm{sec}$, the dynamic receding contact angle became $0^{\circ}$ and fluid was left behind the nozzle. As a result, it was confirmed that residual fluid should be allowed to realize a sufficient scanning speed. Since the contact time of a G2 fluid and a resist becomes longer in such a system, the interaction between a G2 fluid and a resist should be discussed.

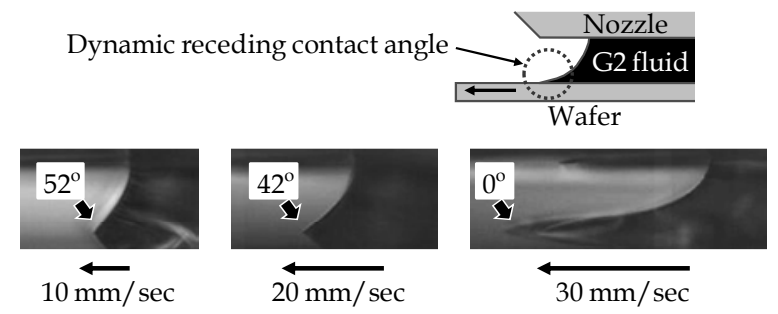

Fig. 20. Side views of the fundamental scanning test. The dynamic receding contact angle on a wafer became $0^{\circ}$ with the scanning speed of $30 \mathrm{~mm} / \mathrm{sec}$.

\subsubsection{Soaking test}

To investigate the interaction between a G2 fluid and a resist, the defect inspection of soaked wafers is effective. Figure 21 shows the procedure of a soaking test. Between the exposure and post-exposure bake (PEB), a wafer was soaked in a G2 fluid for 60 seconds and the fluid was removed by spin drying. The defect inspection was carried out using KLA2371 (KLATencor). The defects induced by post-exposure soaking were evaluated with the above procedure.

Figure 22 shows the results of the defect inspection. A large number of defects were found on the resist after soaking in HIF-E. In a microscopic review, there were many stains as shown in Fig. 22. As a result, it was confirmed that it is necessary to use an inert resist for a G2 fluid. On the other hand, it is not apparent that the wafer soaked in HIF-A or HIF-D had more defects than the reference wafer. There were some variations in the number of defects because the experiment was carried out in off-line process. Defect studies should be done in more clean circumstances. 


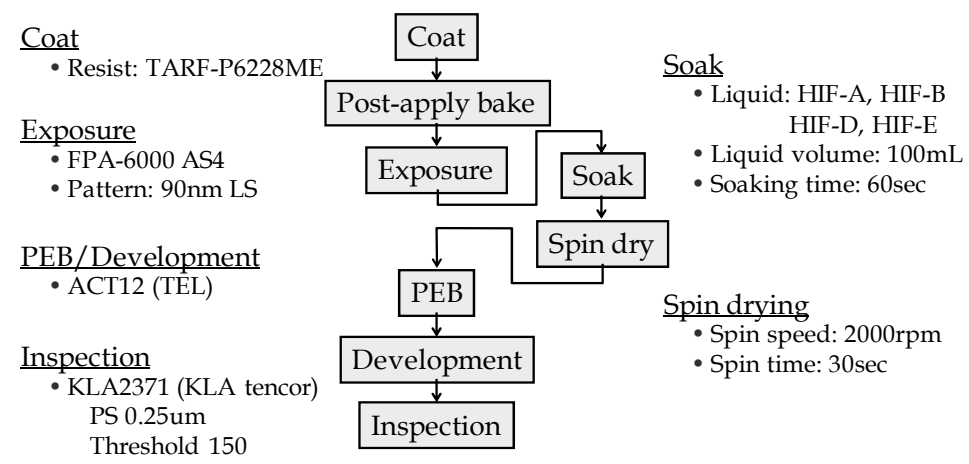

Fig. 21. Experimental procedure of a post-exposure soaking test to investigate the interaction between a G2 fluid and a resist.

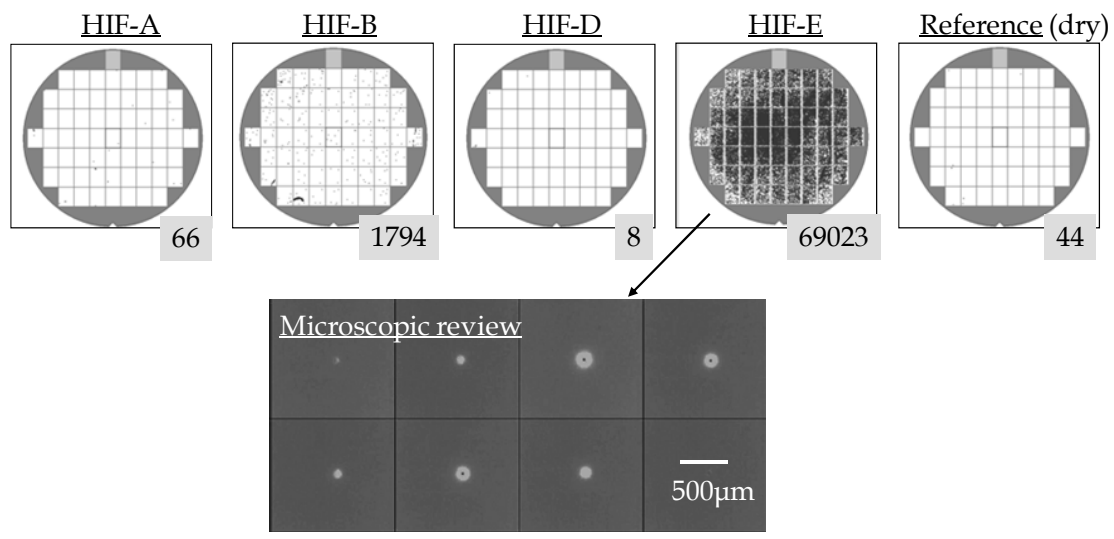

Fig. 22. Results of defect inspection. The number of defects after soaking in HIF-A, B, D, and E are 66, 1794, 8, and 69023, respectively.

\subsubsection{Metal contamination}

If the fluid contains a lot of metals, a wafer would be polluted by metals in the residual fluid. Thus, the objective of the following experiment is to confirm that G2 fluids are sufficiently clean. The requirement is less than $10^{10}$ atoms $/ \mathrm{cm}^{2}$ on a silicon wafer.

The conditions for the experiment are shown in Table 4. At first, a silicon wafer was dipped into a fluid for 5 minutes. Then, the wafer was pulled up and was dried by air blowing. Then, the metal concentrations on the wafer were evaluated by vapor phase decomposition inductively coupled plasma mass spectrometry (VPD/ICP-MS). The detection limit of the spectrometry is $0.03 \times 10^{10}$ atoms $/ \mathrm{cm}^{2}$. The experiment was done twice for each fluid.

Table 5 shows the experimental results. The metal concentrations of the reference mean those on a wafer without dipping into any fluids. In the case of HIF-A, the concentrations of some metals are more than $10^{10}$ atoms $/ \mathrm{cm}^{2}$ (black-out cells in Table 5). On the other hand, HIF-B and D are sufficiently clean. As a result, the residual fluids of HIF-B and D are acceptable from the viewpoint of metal contamination. 


\begin{tabular}{ccc}
\hline \multirow{4}{*}{ Dipping } & Immersion fluid & HIF-A, HIF-B, HIF-D \\
\cline { 2 - 3 } & Volume of fluid & $200 \mathrm{~mL}$ \\
\cline { 2 - 3 } & Dipping time & $5 \mathrm{minutes}$ \\
\cline { 2 - 3 } Analysis & Wafer & Bare Si $(200 \mathrm{~mm} \phi)$ \\
\cline { 2 - 3 } & Method & VPD $/$ ICP-MS \\
\cline { 2 - 3 } & Detuation area & $180 \mathrm{~mm} \phi$ \\
\hline \multirow{2}{*}{ Detection limit } & $0.03 \times 10^{10}$ atoms $/ \mathrm{cm}^{2}$ \\
\hline
\end{tabular}

Table 4. Experimental conditions for metal contamination on a wafer dipped into a G2 fluid.

\begin{tabular}{|c|c|c|c|c|c|c|c|c|c|c|c|c|c|c|c|}
\hline \multirow{2}{*}{ Fluid } & & \multicolumn{14}{|c|}{ Metal concentration $\left(\times 10^{10}\right.$ atoms $\left./ \mathrm{cm}^{2}\right)$} \\
\hline & & $\mathrm{Li}$ & $\mathrm{Na}$ & $\mathrm{Mg}$ & $\mathrm{Al}$ & K & $\mathrm{Ca}$ & $\mathrm{Ti}$ & $\mathrm{Cr}$ & $\mathrm{Mn}$ & $\mathrm{Fe}$ & $\mathrm{Ni}$ & $\mathrm{Cu}$ & $\mathrm{Zn}$ & $\mathrm{Pb}$ \\
\hline \multirow{2}{*}{$\begin{array}{l}\text { Refe- } \\
\text { rence }\end{array}$} & 1 & $<0.03$ & 0.03 & $<0.03$ & 0.03 & $<0.03$ & $<0.03$ & 0.43 & $<0.03$ & $<0.03$ & $<0.03$ & $<0.03$ & $<0.03$ & $<0.03$ & $<0.03$ \\
\hline & 2 & 0.06 & $<0.03$ & $<0.03$ & 0.05 & $<0.03$ & $<0.03$ & 0.32 & $<0.03$ & $<0.03$ & $<0.03$ & $<0.03$ & 0.03 & $<0.03$ & $<0.03$ \\
\hline \multirow{2}{*}{ HIF-A } & 1 & 0.15 & 0.30 & 0.09 & 1.30 & 0.28 & 0.28 & 0.71 & 0.29 & 0.09 & 1.57 & 0.87 & 0.05 & 0.13 & $<0.03$ \\
\hline & 2 & $\begin{array}{l}0.11 \\
\end{array}$ & 0.92 & 0.05 & 0.85 & 0.97 & 0.36 & 0.45 & 0.13 & $\begin{array}{l}0.19 \\
\end{array}$ & 0.82 & 0.40 & 0.04 & 0.10 & $<0.03$ \\
\hline \multirow{2}{*}{ HIF-B } & 1 & $<0.03$ & 0.45 & 0.05 & 0.23 & 0.13 & 0.38 & 0.48 & $<0.03$ & $<0.03$ & 0.10 & $<0.03$ & 0.04 & 0.20 & $<0.03$ \\
\hline & 2 & $<0.03$ & 0.48 & 0.07 & 0.29 & $\begin{array}{l}0.14 \\
\end{array}$ & $\begin{array}{l}0.47 \\
\end{array}$ & 0.58 & $<0.03$ & $<0.03$ & 0.06 & $<0.03$ & 0.03 & 0.40 & $<0.03$ \\
\hline \multirow{2}{*}{ HIF-D } & 1 & $<0.03$ & 0.36 & 0.12 & 0.57 & 0.10 & 0.21 & 0.51 & $<0.03$ & $<0.03$ & 0.09 & $<0.03$ & 0.07 & 0.06 & $<0.03$ \\
\hline & 2 & $<0.03$ & 0.26 & 0.09 & 0.47 & 0.13 & 0.17 & 0.66 & $<0.03$ & $<0.03$ & 0.10 & $<0.03$ & 0.04 & 0.03 & $<0.03$ \\
\hline
\end{tabular}

Table 5. Metal concentrations on a wafer evaluated by VPD/ICP-MS.

\subsubsection{Dissolved oxygen}

Oxygen in the atmosphere diffuses into the residual fluid on a wafer. When the oxygen-rich residual fluid goes back under the lens, it decreases the transparency of the fluid under the lens. That is the reason why dissolved oxygen is one of the issues arising with a residual fluid. Oxygen concentration in the fluid under the lens was evaluated while a wafer was moving along the sequence as shown in Fig. 23. HIL-203 (JSR) was used as a G2 fluid. A prototype immersion nozzle designed for a G2 fluid was used for the experiment. The processing time for one wafer was 30 seconds and it consisted of a scanning time and a waiting time at the edge of the stage. The fluid under the lens was sucked through the hole opened in the lens and the oxygen concentration in the sucked fluid was measured. The absorbance was calculated by using the relation as shown in Fig. 4.

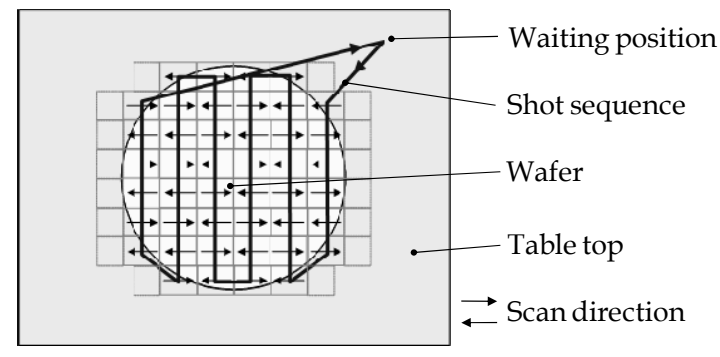

Fig. 23. Sequence of a scanning test on an 8 inches wafer.

Figure 24 shows fluid absorbance induced by dissolved oxygen against the number of scanned wafers. The absorbance rises with the scanning speed but it is low enough even at 
the scanning speed of $800 \mathrm{~mm} / \mathrm{sec}$. This result exhibits that the nozzle can reduce the amount of residual fluid sufficiently and can suppress the fluid darkening. In conclusion, the issue of dissolved oxygen was solved by the immersion nozzle designed for a G2 fluid.

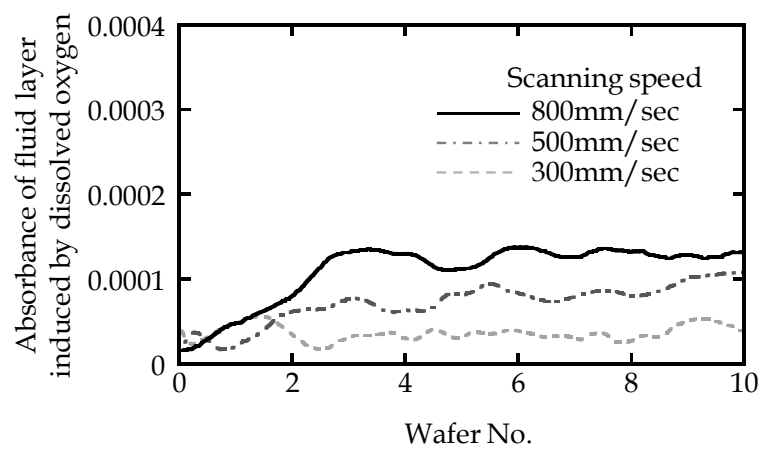

Fig. 24. Fluid absorbance between a lens and a wafer during the scan. The absorbance induced by dissolved oxygen is low enough even at the scanning speed of $800 \mathrm{~mm} / \mathrm{sec}$.

\section{Remaining challenges}

There are some remaining challenges to realize high-index immersion lithography. As described in the second subchapter, the quality of LuAG material does not reach the target specification. Especially, the absorbance of LuAG would be a critical issue. While the intrinsic absorbance of LuAG is lower than the target absorbance, further reduction of impurities is required.

On the other hand, there still remain a few issues to be studied in an immersion system using a G2 fluid. Although fluid absorbance can be kept low enough, dose homogeneity through a fluid layer should be confirmed. Defect study should be done with various resists. It is preferable to examine them with a preproduction tool using a G2 fluid.

For the extendability of high-index immersion lithography, the research activity on new materials such as G3 fluids and high-index resists is needed.

\section{Conclusion}

It has been discussed the feasibility on a high-index immersion system of 1.55 NA using LuAG and a G2 fluid. Although the IBR correction of LuAG is feasible, the quality of LuAG is not enough and the acceleration of its development is desired. The immersion system using a G2 fluid is being developed without serious issues. It was demonstrated that fluid absorbance can be kept low enough through an in-line purification unit and an oxygen removal unit. Lens contamination can be suppressed by addition of a small amount of water into a G2 fluid. Some issues arising with residual fluid, such as fluid darkening due to reentry of oxygen-rich residual fluid, were solved. By accepting residual fluid on a wafer, the scanning speed and the throughput can be raised.

EUVL is the orthodox candidate of the next generation lithography but still needs real verifications in various items. If EUVL is delayed, high-index immersion lithography will be at the leading edge lithography. It is a common knowledge that strong supports from the 
industry are indispensable to overcoming the remaining challenges such as LuAG. It is just said, "No market, no tool."

\section{Acknowledgment}

The author would like to acknowledge DuPont, JSR, and Mitsui Chemicals for supplying G2 fluids and purification units. The author also thanks colleagues for their cooperation.

\section{References}

Parthier, L.; Wehrhan, G.; Seifert, F.; Ansorg, M.; Aichele, T. \& Seitz, C. (2008). High-index lens material LuAG: development status and progress, presented at SEMATECH Litho Forum, Bolton Landing, New York, USA, May 12-14, 2008

Parthier, L.; Wehrhan, G.; Seifert, F.; Ansorg, M.; Aichele, T.; Seitz, C. \& Letz, M. (2008). Development update of high index lens material LuAG for ArF hyper NA immersion systems, presented at 5th Int. Symp. on Immersion Lithography, HI-01, The Hague, Netherlands, September 22-25, 2008

Burnett, J. H.; Kaplan, S. G.; Shirley, E. L.; Horowitz, D.; Josell, D.; Clauss, W.; Grenville, A. \& Peski, C. V. (2006). High index materials for $193 \mathrm{~nm}$ immersion lithography, presented at 3rd Int. Symp. on Immersion Lithography, OO-21, Kyoto, Japan, October 25,2006

Nawata, T.; Inui, Y.; Masada, I.; Nishijima, E.; Mabuchi, T.; Mochizuki, N.; Satoh, H. \& Fukuda, T. (2007). High-index fluoride materials for $193 \mathrm{~nm}$ immersion lithography, Proc. SPIE Vol. 6520, 65201P

Letz, M.; Gottwald, A.; Richter, M.; Liberman, V. \& Parthier, L. (2010). Temperaturedependent Urbach tail measurements of lutetium aluminum garnet single crystals, Phys. Rev. B 81, 155109

French, R. H.; Liberman, V.; Tran, H. V.; Feldman, J.; Adelman, D. J.; Wheland, R. C.; Qiu, W.; McLain, S. J.; Nagao, O.; Kaku, M.; Mocella, M.; Yang, M. K.; Lemon, M. F.; Brubaker, L.; Shoe, A. L.; Fones, B.; Fischel, B. E.; Krohn, K.; Hardy, D. \& Chen, C. Y. (2007). High-index immersion lithography with second-generation immersion fluids to enable numerical aperatures of 1.55 for cost effective 32-nm half pitches, Proc. SPIE Vol. 6520, 65201O

Furukawa, T.; Kishida, T.; Miyamatsu, T.; Kawaguchi, K.; Yamada, K.; Tominaga, T.; Slezak, M. \& Hieda, K. (2007). High-refractive index materials design for ArF immersion lithography, Proc. SPIE Vol. 6519, 65190B

Kagayama, A.; Wachi, H.; Namai, Y. \& Fukuda, S. (2007). High-refractive index fluids for second-generation 193-nm immersion lithography, persented at SPIE Advanced Lithography, 6519-66, San Jose, California, USA, February 25-March 2, 2007

Zimmerman, P. A.; Byers, J.; Rice, B.; Ober, C. K.; Giannelis, E. P.; Rodriquez, R.; Wang, D.; O'Connor, N.; Lei, X.; Turro, N. J.; Liberman, V.; Palmacci, S.; Rothschild, M.; Lafferty, N. \& Smith, B. W. (2008). Development and evaluation of a 193nm immersion generation-three fluid candidates, Proc. SPIE Vol. 6923, 69230A

Sakai, K.; Iwasaki, Y.; Mori, S.; Yamada, A.; Ogusu, M.; Yamashita, K.; Nishikawara, T.; Hara, S. \& Watanabe, Y. (2008). Feasibility study on immersion system using highindex materials, Jpn. J. Appl. Phys. Vol. 47, No. 6, pp. 4853-4861 
French, R. H.; Qiu, W.; Yang, M. K.; Wheland, R. C.; Lemon, M. F.; Shoe, A. L.; Adelman, D. J.; Crawford, M. K.; Tran, H. V.; Feldman, J.; McLain, S. J. \& Peng, S. (2006). Second generation fluids for 193nm immersion lithography, Proc. SPIE Vol. 6154, 615415

Santillan, J.; Otoguro, A.; Itani, T.; Fujii, K.; Kagayama, A.; Nakayama, N.; Tamatani, H. \& Fukuda, S. (2006). Novel high refractive index fluids for 193-nm immersion lithography, Proc. SPIE Vol. 6154, 61544Q

Sekine, Y.; Kawashima, M.; Sakamoto, E.; Sakai, K.; Yamada, A. \& Honda, T. (2007). Feasibility of 37-nm half-pitch with ArF high-index immersion lithography, Proc. SPIE Vol. 6520, 65201Q

French, R. H.; Yang, M. K.; Peng, S.; Qiu, W.; Wheland, R. C.; Lemon, M. F.; Crawford, M. K.; Sewell, H.; McCafferty, D. \& Markoya, L. (2005). Imaging of 32-nm 1:1 lines and spaces using 193-nm immersion interference lithography with second-generation Immersion fluids to achieve a numerical aperture of 1.5 and a $\mathrm{k} 1$ of $0.25, \mathrm{~J}$. Microlith., Microfab., Microsyst. Vol. 4, 3, 031103

Wang, Y.; Miyamatsu, T.; Furukawa, T.; Yamada, K.; Tominaga, T.; Makita, Y.; Nakagawa, H.; Nakamura, A.; Shima, M.; Kusumoto, S.; Shimokawa, T. \& Hieda, K. (2006). High-refractive-index fluids for the next generation ArF immersion lithography, Proc. SPIE Vol. 6153, 61530A

Furukawa, T.; Hieda, K.; Wang, Y.; Miyamatsu, T.; Yamada, K.; Tominaga, T.; Makita, Y.; Nakagawa, H.; Nakamura, A.; Shima, M. \& Shimokawa, T. (2006). High refractive index fluid for next generation ArF immersion lithography, J. Photopolym. Sci. Technol. Vol. 19, 5, pp. 641-646

Gejo, J. L.; Kunjappu, J. T.; Zhou, J.; Smith, B. W.; Zimmerman, P.; Conley, W. \& Turro, N. J. (2007). Outlook for potential third-generation immersion fluids, Proc. SPIE Vol. 6519,651921

Liberman, V.; Rothschild, M.; Palmacci, S. T.; Zimmerman, P. A. \& Grenville, A. (2007). Laser durability studies of high-index immersion fluids: fluid degradation and optics contamination effects, Proc. SPIE Vol.6520, 652035

Sakai, K.; Mori, S.; Sakamoto, E.; Iwasaki, Y.; Yamashita, K.; Hara, S.; Watanabe, Y. \& Suzuki, A. (2008). Progress of high-index immersion exposure system, presented at 5th Int. Symp. on Immersion Lithography, HI-06, The Hague, Netherlands, September 22-25, 2008

Honda, T.; Kishikawa, Y.; Tokita, T.; Ohsawa, H.; Kawashima, M.; Ohkubo, A.; Yoshii, M.; Uda, K. \& Suzuki, A. (2004). ArF immersion lithography: critical optical issues, Proc. SPIE Vol. 5377, pp. 319-328

Kubo, H.; Hata, H.; Sakai, F.; Deguchi, N.; Iwanaga, T. \& Ebihara, T. (2007). Immersion exposure tool for the 45-nm HP mass production, Proc. SPIE Vol. 6520, 65201X

Sewell, H.; Mulkens, J.; Graeupner, P.; McCafferty, D.; Markoya, L.; Donders, S.; Samarakone, N. \& Duesing, R. (2007). Extending immersion lithography with high index materials, Proc. SPIE Vol. 6520, 65201M

Shedd, T. A.; Schuetter, S. D.; Nellis, G. F. \& Peski, C. V. (2006). Experimental characterization of the receding meniscus under conditions associated with immersion lithography, Proc. SPIE Vol. 6154, 61540R

Sanders, D. P.; Sundberg, L. K.; Brock, P. J.; Ito, H.; Truong, H. D.; Allen, R. D.; McIntyre, G. R. \& Goldfarb, D. L. (2008). Self-segregating materials for immersion lithography, Proc. SPIE Vol. 6923, 692309 


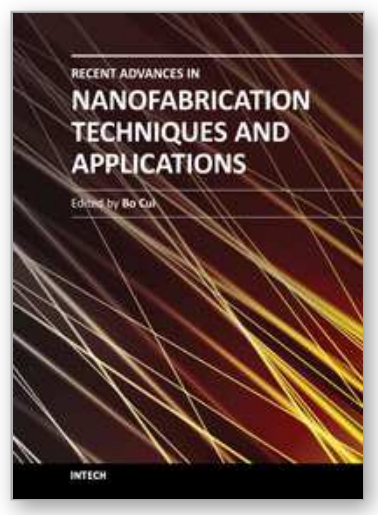

\author{
Recent Advances in Nanofabrication Techniques and Applications \\ Edited by Prof. Bo Cui
}

ISBN 978-953-307-602-7

Hard cover, 614 pages

Publisher InTech

Published online 02, December, 2011

Published in print edition December, 2011

Nanotechnology has experienced a rapid growth in the past decade, largely owing to the rapid advances in nanofabrication techniques employed to fabricate nano-devices. Nanofabrication can be divided into two categories: "bottom up" approach using chemical synthesis or self assembly, and "top down" approach using nanolithography, thin film deposition and etching techniques. Both topics are covered, though with a focus on the second category. This book contains twenty nine chapters and aims to provide the fundamentals and recent advances of nanofabrication techniques, as well as its device applications. Most chapters focus on indepth studies of a particular research field, and are thus targeted for researchers, though some chapters focus on the basics of lithographic techniques accessible for upper year undergraduate students. Divided into five parts, this book covers electron beam, focused ion beam, nanoimprint, deep and extreme UV, X-ray, scanning probe, interference, two-photon, and nanosphere lithography.

\title{
How to reference
}

In order to correctly reference this scholarly work, feel free to copy and paste the following:

Keita Sakai (2011). High-Index Immersion Lithography, Recent Advances in Nanofabrication Techniques and Applications, Prof. Bo Cui (Ed.), ISBN: 978-953-307-602-7, InTech, Available from:

http://www.intechopen.com/books/recent-advances-in-nanofabrication-techniques-and-applications/high-indeximmersion-lithography

\section{INTECH}

open science | open minds

\section{InTech Europe}

University Campus STeP Ri

Slavka Krautzeka 83/A

51000 Rijeka, Croatia

Phone: +385 (51) 770447

Fax: +385 (51) 686166

www.intechopen.com

\section{InTech China}

Unit 405, Office Block, Hotel Equatorial Shanghai

No.65, Yan An Road (West), Shanghai, 200040, China

中国上海市延安西路65号上海国际贵都大饭店办公楼405单元

Phone: +86-21-62489820

Fax: $+86-21-62489821$ 
(C) 2011 The Author(s). Licensee IntechOpen. This is an open access article distributed under the terms of the Creative Commons Attribution 3.0 License, which permits unrestricted use, distribution, and reproduction in any medium, provided the original work is properly cited. 